\title{
Membrane versus soluble isoforms of TNF a exert opposing effects on tumor growth and survival of tumor-associated myeloid cells
}

\author{
Shidrokh Ardestani ${ }^{1}$, Bin $\mathrm{Li}^{1}$, Desirae L. Deskins ${ }^{1}$, Huiyun $\mathrm{Wu}^{2}$, Pierre P. Massion ${ }^{3,5}$, and \\ Pampee P. Young ${ }^{1,4,5}$ \\ ${ }^{1}$ Department of Pathology, Microbiology and Immunology, Vanderbilt University Medical Center, \\ Nashville, TN, 37232, USA \\ 2Department of Biostatistics and Vanderbilt-Ingram Cancer Center/Cancer Biostatistics Center, \\ Vanderbilt University Medical Center, Nashville, TN, 37232, USA \\ ${ }^{3}$ Department of Medicine, Vanderbilt Ingram Cancer Center, Vanderbilt University Medical \\ Center, Nashville, TN, 37232, USA \\ ${ }^{4}$ Department of Internal Medicine, Vanderbilt University Medical Center, Nashville, TN, 37232, \\ USA \\ ${ }^{5}$ Department of Veterans Affairs Medical Center, Nashville, TN, 37212 USA
}

\begin{abstract}
TNFa, produced by most malignant cells, orchestrates the interplay between malignant cells and myeloid cells, which have been linked to tumor growth and metastasis. Although TNFa can exist as one of two isoforms, a 26-kDa membrane tethered form (mTNFa) or a soluble 17-kDa cytokine (sTNFa), the vast majority of published studies have only investigated the biological effects of the soluble form. We demonstrate for the first time that membrane and soluble isoforms have diametrically opposing effects on both tumor growth and myeloid content. Mouse lung and melanoma tumor lines expressing mTNFa, generated small tumors devoid of monocytes versus respective control lines or lines expressing sTNFa. The lack of myeloid cells was due to a direct effect of mTNFa on myeloid survival via induction of cell necrosis by increasing reactive oxygen species. Human NSCLCs expressed varying levels of both soluble and membrane TNFa, and gene expression patterns favoring $\mathrm{mTNFa}$ were predictive of improved lung cancer survival. These data suggest that there are significant differences in the role of different $\mathrm{TNFa}$ isoforms in tumor progression and the bioavailability of each isoform may distinctly regulate tumor progression. This insight is critical for effective intervention in cancer therapy with the available TNFa inhibitors, which can block both TNFa isoforms.
\end{abstract}

\section{Keywords}

Membrane-Tumor Necrosis Factor-alpha; Tumor Associated Myeloid Cells; ROS; TACE; NSCLC

\footnotetext{
Corresponding author: Pampee P. Young, Vanderbilt University School of Medicine, Department of Pathology Microbiology Immunology, 1161 21st Avenue South, C2217A MCN, Nashville, TN 37232. Phone: 615-936-1098; Fax: 615-343-7023; pampee.young@vanderbilt.edu.

Conflict of Interest: The authors declare no conflict of interest.
} 


\section{INTRODUCTION}

TNFa is a major inflammatory cytokine expressed within the tumor microenvironment. $\mathrm{TNFa}$ is not normally detected in the serum of healthy individuals, but elevated levels have been detected in patients with prostate, pancreatic, renal cell, hematopoietic and metastatic breast cancers (1-6). The role of TNFa in cancer progression is conflicting. Multiple studies have demonstrated a pro-tumorogenic role of TNFa in vivo, in part by inhibiting necrosis of and by stimulating a proangiogenic myeloid phenotype $(7,8)$. Despite the growing body of evidence showing that TNFa can function as a tumor promoter, there remain conflicting findings. Several case reports describe a temporal relationship between development of skin malignancies and lymphoma and the use of TNFa inhibitors $(9,10)$. Moreover, the use of infliximab, which prevents binding of TNFa to its receptors, does not improve clinical outcome in renal cell carcinoma (11). Collectively, these data demonstrate the complexity of $\mathrm{TNFa}$ in cancer pathogenesis.

The majority of studies to date focus on the $17-\mathrm{kDa}$ soluble moiety of TNFa, which is released after proteolytic cleavage of the 26-kDa type II transmembrane isoform by TNFaconverting enzyme (TACE; ADAM-17) (12). The role of membrane form of TNFa and its expression pattern in different tissue is poorly understood. Cardiac-restricted expression of membrane versus soluble TNFa isoform has been shown to have adverse effect in cardiac remodeling $(13,14)$. Expression of sTNFa in cardiomyocytes can cause dilation of left ventricle in mice whereas the mTNFa results in a concentric hypertrophic cardiac phenotype. Increased mTNFa expression on T-cells is shown to modulate monocytes IL10 production (15). In spite of these findings, the role of mTNFa in tumor biology is unknown (13). Thus far it is not known whether tumors can express both isoforms. In addition there is little understanding of the difference in the mechanism of action of sTNFa versus mTNFa in regulating tumor behavior or impact on the tumor inflammatory stroma.

The goal of the current study was to assess if the conflicting data regarding the association of TNFa with tumor progression was due to distinct effects of tumor expression of membrane vs. soluble isoforms. We found that whereas sTNFa expression promoted tumor growth, mTNFa-expressing tumors exhibited reduced growth and were largely devoid of myeloid cells. Our study demonstrated distinct TNFa isoform-dependent effects on myeloid cell survival. Importantly, we showed for the first time that human non-small cell lung cancer (NSCLC) tissues exhibit differential expression of membrane versus soluble TNFa. Moreover, patients with lung tumors predicted by the molecular signature to have higher mTNFa had better survival when compared to patients with tumors with higher soluble form of TNFa expression. Together, these data demonstrate that opposing functions of membrane versus soluble TNFa significantly impact tumor progression for several cancer types, including NSCLC, one of the most commonly diagnosed cancer in the United States and one of the most difficult to treat (16). Strategies for molecularly targeted anti-TNFa agents must include screening patients for expression of each isoform and tailoring inhibitors to specifically target the soluble isoform.

\section{MATERIALS AND METHODS}

\section{Mice and cell lines}

Wild-type C57Bl/6 (WT) mice were purchased from Jackson Laboratory. Homozygous mutants for TNFR1 and R2 knockout (TNFR-DKO) on a C57Bl/6 background were a generous gift from Dr. D. Polk. Lewis Lung Carcinoma (LLC), B16F10 melanoma, and RAW 264.7 cells were purchased from American Type Culture Collection (ATCC) and maintained in DMEM supplemented with glucose (4.5 g/l) along with penicillin (10 U/L), streptomycin $(10 \mu \mathrm{g} / \mathrm{ml})$, plasmocin $(25 \mu \mathrm{g} / \mathrm{ml})$, amphotericin-B $(2.5 \mu \mathrm{g} / \mathrm{ml})$. H520, 
HCC95, SW900, H157, HCC15, and A549 were provided by Dr. P. P. Massion and were maintained in RPMI 1640 medium (Gibco). A549 cells were maintained in Ham's F-12K medium (Gibco). All cell lines were supplied with $10 \%(\mathrm{v} / \mathrm{v})$ fetal bovine serum and incubated at $37^{\circ} \mathrm{C}$ in $5 \% \mathrm{CO}_{2}$.

\section{Constructs and retroviral transductions}

Secretable TNFa was generated by replacing amino acids -76 to -1 containing the cytoplasmic signal-anchor for type II membrane protein and a short extracellular region with a sequence coding for the IL-2 signal peptide (IL2sp, amino acids -20 to -1 ) that directs the transport of TNFa to the outer cellular space and produces a solely secretable form of 17$\mathrm{kDa}$ TNFa This was done by amplifying mouse wild-type TNFa cDNA using forward primers flanked by BamH1-IL2sp. The amplified fragment was isolated and purified by gel electrophoresis. The restriction sites at each end allowed ligation of the IL2sp-TNFa fragment into the BamH1-EcoR1 site of LZRS-IRES-Neo retroviral vector, conferring neomycin resistance. The $\mathrm{mTNF} \Delta 1-9, \mathrm{~K} 11 \mathrm{E}$ sequence encoding a mutant transmembrane $\mathrm{TNFa}$ molecule with a deletion at the cleavage site between presequnce and mature membrane TNFa (BCCM/LMBP plasmid collection, Ghent University) was also cloned into LZRS. This mutation prevents cleavage of the 26-kDa membrane TNFa into secretory TNFa isoform. An empty LZRS vector was used as a control vector.

\section{Surface expression of TNFa}

Cells were detached from tissue culture plate and incubated with anti-TNFa antibody $(1 \mu \mathrm{l} /$ $2.5 \times 10^{4}$ cells, Southern Biotech) for 30 minutes on ice without permeabilization. PE conjugated secondary antibody $\left(0.125 \mu \mathrm{g} / 10^{6}\right.$ cells $\left./ 100 \mu \mathrm{l}\right)$ was added for $30 \mathrm{~min}$ on ice. Surface expression of TNFa was measured using flow cytometry. Data are presented as percent of viable cells.

\section{In vivo murine tumor model}

Control, IL2spTNFa, and mTNFa cell lines $\left(10^{6}\right.$ cells in $100 \mu$ l of PBS) were implanted subcutaneously into WT, TNFR-DKO or TNFR-DKO-BMT mice. Mice were sacrificed 15 days post-implantation, tumors were excised and the volume was calculated by multiplying tumor length by width by height.

\section{BrdU assay}

The BrdU ELISA was performed according to the manufacturer's instructions. Briefly, 1000 cells/well were seeded in triplicate in a 96-well plate. Cells were allowed to attach for 8 hours. BrdU label was added to each well and incubated for an additional 24 hours. Absorbance was analyzed at $450-540 \mathrm{~nm}$.

\section{Cell viability assay}

Cell viability was measured by seeding 5000 cells/well in a $96-w e l l$ plate for 48 hours. Cells were labeled with $100 \mu \mathrm{l}$ of PBS containing $0.5 \mathrm{mg} / \mathrm{mL}$ of 3-[4,5-dimethylthiazol-2-yl] 2,5,diphenyltetrazolium bromide (MTT) (Sigma). After 2 hours of incubation at $37^{\circ} \mathrm{C}$, cells were lysed with $0.1 \mathrm{ml}$ DMSO. Photometric measurement was carried out at $540 \mathrm{~nm}$.

\section{Leukocyte quantification in tumors}

Tumor tissues were finely minced and incubated in $5 \mathrm{~mL}$ dissociation solution (RPMI medium supplemented with $5 \%$ FBS, and $1 \mathrm{mg} / \mathrm{mL}$ of Collagenase type IV (Worthington)) for $30 \mathrm{~min}$ at $37^{\circ} \mathrm{C}$. To obtain a single-cell suspension, cells were passed through $70-\mu \mathrm{m}$ nylon cell strainer (Becton Dickinson, NJ). Cells were washed with FACS buffer (PBS, 2 $\mathrm{mM}$ EDTA, $0.5 \% \mathrm{BSA}$ ) and incubated for $5 \mathrm{~min}$ in RBC lysis buffer solution $(155 \mathrm{mM}$ 
$\mathrm{NH} 4 \mathrm{Cl}, 12 \mathrm{mM}$ NaHCO3, $0.1 \mathrm{mM}$ EDTA). Cells were washed twice in FACS buffer and incubated with anti-CD3 (Biolegend), -Ly6G (BD Pharminogen), -F480 (eBioscience) and $\mathrm{CD} 11 \mathrm{~b}+$ (BD Pharminogen). After two washes, labeled cells were resuspended in vital dye 7-AAD (BD Pharminogen) and subjected to flow cytometry on LSRFortessa flow cytometer (Becton, Dickinson and Company, Franklin Lakes, NJ) and analyzed by using FlowJo software (TreeStar, Ashland, OR).

\section{Myeloid cell-trafficking to tumor}

Control vector or mTNFa-expressing tumor cells were injected subcutaneously into wildtype mice. After 12 days, freshly isolated myeloid cells were labeled with 5(6)Carboxyfluorescein N-hydroxysuccinimidyl ester (CFSE) fluorescent tracking dyes and injected into retro-orbital space $\left(5 \times 10^{6}\right.$ cells/animal $)$. Eighteen hours later, tumors were harvested and single-cell suspensions were made. CFSE labeled cells were detected using flow cytometry.

\section{Caspase $3 / 7$ activity}

Freshly isolated CD11b+ (10 $5 / 96$-well) were cocultured with fixed control, control + recTNFa $(100 \mathrm{U} / \mathrm{mL})$, and mTNFa B16F10 cells at CD11b+/tumor cells ratio of 1:10 for 5 hours. Apoptosis was quantified in the form of caspase-3/7 activation using the Apo-One fluorometric assay system from Promega Corporation (Madison, WI) according to the manufacturer's protocol.

\section{Measurement of intracellular ROS}

The oxidant-sensing probe CM-H2DCFDA (Invitrogen) was used to detect intracellular reactive oxygen species (ROS). Freshly isolated CD11b+ cells were loaded with $10 \mu \mathrm{M}$ CM-H2DCFDA, and cocultured with fixed B16F10 control, control+100 U/ml of recombinant TNFa, mTNFa or mTNFa $+2 \mathrm{mM} \mathrm{N}$-acetyl-cysteine (NAC) for 8 hours. Fluorescence was determined using a luminescence spectrophotometer (Spectra max, Molecular Devices) with an excitation wavelength of $429 \mathrm{~nm}$ and emission wavelength of $517 \mathrm{~nm}$.

\section{Survival analysis}

A cohort published by Shedden et al. was analyzed for disease-free survival (17). The data set included gene-expression profiles for 442 lung adenocarcinomas with high-quality geneexpression data, pathological data and clinical information. The association between gene expression and the survival was examined using the Cox proportional hazard model. Kaplan-Meier curves were generated to visualize the survival pattern by dichotomizing the gene-expression. The subgroup analysis of mTNFa and TACE was done by dividing the cohort into 4 groups of high TNFa with high/low TACE or low TNFa with high/low TACE. Log-rank overall tests were performed for the 4 groups. All statistical analyses were performed using R (www.r-project.org).

\section{Statistical analysis}

The statistical significance between experimental and control groups was determined by Student's $t$-test or ANOVA followed by Tukey's post-test using Prism software (Graphpad, San Diego, CA). A $P$-value of $<0.05$ was considered statistically significant. 


\section{RESULTS}

\section{mTNFa isoform reduces tumor growth}

In this study we investigated the effects of different TNFa isoforms on malignant tumor phenotypes using murine Lewis Lung Carcinoma (LLC) sublines expressing either sTNFa (LZRS-IRES-IL2spTNFa) or mTNFa (LZRS-IRES-mTNF 1 1-9) by retroviral transduction (Fig. 1A). Cells transduced with empty vector (LZRS-IRES-Neo) were used as control. Untransduced LLC cells exhibited undetectable levels of TNFa expression as determined by ELISA. The relative expression of sTNFa and cell surface expression of TNFa by transduced cells were confirmed by ELISA and flow cytometry respectively. sTNFa expression was detected in IL2spTNFa-expressing cells at $5 \mathrm{ng} / \mathrm{ml}$. Surface expression of TNFa was not detected in control and IL2spTNFa tumor cells (mean fluorescent intensity of 150 and 202 respectively). In contrast, mTNFa-expressing LLC cells displayed 7.1- and 5.3-fold increase in surface TNFa as compared with control and IL2spTNFa, respectively (Fig. 1B).

To evaluate whether overexpressing various TNFa isoforms affected growth or survival of tumor cells, we assessed in vitro proliferation and viability using the BrdU incorporation and MTT assay, respectively. Both IL2spTNFa and mTNFa-expressing cells exhibited similar in vitro growth rates compared with control LLC lines ( $P>0.05$; Fig. 1C). IL2spTNFa and mTNFa LLC cell lines tested for viability also displayed similar levels of survival rate compared to control ( $P>0.05$; Fig. 1D). To gain additional evidence that the membrane isoform did not reduce survival or viability and that these observations were not cell specific, we transduced B16F10-melanoma cell lines with retroviral constructs, containing mTNFa or an empty construct as control cells. Similar to LLC lines, the proliferation rate $(P>0.05)$ and viability $(P>0.05)$ were not affected in mTNFa-expressing B16F10 cells compared to control cells (Supplementary Fig. S1A and B). These findings are consistent with earlier studies in which we showed that overexpressing the wild-type TNFa in both LLC and B16F10 melanoma did not alter in vitro growth (8).

LLC cell lines expressing soluble (IL2spTNFa) or membrane (mTNFa) isoforms were implanted subcutaneously into the flank of wild-type C57Bl/6 mice (WT). The same number of cells transduced with empty vector was implanted as a control. After 14 days, LLC tumors expressing IL2spTNFa were $\sim 7$ fold $\left(1214 \pm 122 \mathrm{~mm}^{3}\right)$ larger compared to control tumors $\left(124.4 \pm 92 \mathrm{~mm}^{3} ; \mathrm{n}=5, P<0.0005\right.$; Fig. 1E). By contrast, tumors expressing $\mathrm{mTNFa}$ exhibited $65 \%$ reduction in tumor volume $\left(105.8 \pm 29.3 \mathrm{~mm}^{3}\right)$ compared to control tumor $\left(294.1 \pm 35.9 \mathrm{~mm}^{3}\right)(\mathrm{n}=12, P<0.0005$; Fig. 1F). Similar growth reduction was observed with mTNFa-expressing B16F10 tumors cell line when compared with matched controls $(\mathrm{n}=7$, $P<0.05$; Fig. $1 \mathrm{G}$ ). In addition, tumor weight measurement followed similar pattern to tumor volume as presented in Supplementary Fig. S2A-C. These data suggested that different $\mathrm{TNFa}$ isoforms have opposing effects on tumor size.

\section{Expression of mTNFa does not affect tumor proliferation or vascularity in vivo}

To evaluated tumor vascular density and tumor cell proliferation rate, histological sections from control, IL2spTNFa and mTNFa LLC tumor were immunostained with platelet/ endothelial cell adhesion molecule-1 (PECAM-1) antibody to evaluate microvessel density, and anti-Ki67 to assess tumor cell proliferation (Fig. 2A). Histomorphometry of PECAM-1positive areas showed no difference in vascular density amongst the tumors expressing different TNFa isoforms versus control ( $P>0.05$; Fig. $2 \mathrm{~B})$. Furthermore, IL2spTNFa and mTNFa-expressing LLC tumors showed no significant difference in immunoreactivity with the Ki-67 antibody compared to control tumors ( $P>0.05$; Fig. $2 \mathrm{C})$. 
Vascular density and cell proliferation analyses were also performed between B16F10 melanoma-derived tumors expressing mTNFa versus control (Supplementary Fig. S3A). Similar to LLC tumors, no significant difference was observed in microvessel density and in vitro proliferation between the control and $\mathrm{mTNFa}$-expressing melanoma tumors $(P>0.05$; Supplementary Fig. S3B and C).

\section{mTNFa-expressing tumors are devoid of tumor associated myeloid cells}

It is often assumed that TNFa-mediated tumor promotion is secondary to TNFa-mediated inflammation. To determine whether mTNFa-expressing tumors had altered composition of inflammatory cells, we quantified LLC tumor-associated T-cells (anti-CD3), B-cells (antiB220b), neutrophils (anti-Ly6G) and myeloid-monocytic lineage (anti-ER-HR3, CD11b, F4/80) using immunohistochemistry staining and flow cytometric analysis of single-cell suspension of tumors. Both immunostaining and flow cytometric analysis showed no significant difference in T-cell content among control, IL2sp TNFa and mTNFa-expressing tumor cells (Supplementary Fig. S4A-C). Anti-B220b staining revealed only rare, infiltrating B-cells for all tumor groups (data not shown). Flow cytometric analysis of antiLy6G showed no significant difference in neutrophils population within control and mTNFa-expressing tumors ( $P>0.05$; Supplementary Fig. S4D). Interestingly when we evaluated tumor-associated myeloid cell population a significant difference was observed in mTNFa-expressing tumors compared to control and IL2spTNFa tumors. Histological staining of mTNFa-expressing LLC tumors for ER-HR3, a myeloid marker reactive to $\sim 70 \%$ of circulating monocytes and a subset of mature tissue macrophages (18), had fewer number of infiltrated ERHR3 + cells $(0.04 \pm 0.02 \%)$ versus control $(6.4 \pm 0.37 \%)$ or IL2spTNFa tumors $(16 \pm 1.03 \%)(P>0.005$; Fig. $3 \mathrm{C}$ and D). Further evaluation of single-cell suspension of tumors showed significantly lower number of CD11b+ myeloid cells $(52.17 \pm 6.1 \% ; P>0.005)$ and $\mathrm{F} 4 / 80$ macrophages $(3.75 \pm 2.4 \% ; P>0.005)$ in $\mathrm{mTNFa}-$ expressing tumors as compared to control (Fig. 3A-F). Anti-F4/80 staining of tumor sections further confirmed the significant reduction of F4/80-positive macrophages in mTNFa expressing tumors (Fig. $3 \mathrm{G}$ and $\mathrm{H}$ ).

To test whether the tumor inhibitory effects of $\mathrm{mTNFa}$ required the presence of TNFa receptors, tumor growth was assessed in TNFa receptors deficient mice (TNFa-R1 and TNFa-R2 double knockout, TNFR-DKO). Mice were implanted with LLC cell line expressing various TNFa isoforms. LLC lines expressing $\mathrm{mTNFa}$ isoform did not generate significantly smaller tumors $\left(110.5 \pm 17.6 \mathrm{~mm}^{3}\right)$ in compared with their paired control tumors $\left(161.7 \pm 29.6 \mathrm{~mm}^{3}, \mathrm{n}=5\right)(P>0.05$; Supplementary Fig. S5A). In addition implantation of mTNFa-expressing LLC tumor cells in TNFR-DKO mice restored the ER-HR3 ${ }^{+}$myeloid population in $\mathrm{mTNFa}$-expressing tumors $(0.91 \pm 0.16 \%$ ER-HR positive area/total area in mTNFa vs. $0.67 \% \pm 0.16 \%$ in control; $P>0.05$; Supplementary Fig. S5B). Similar results were observed in B16F10 line (data not shown).

Restoration of myeloid cell population in mTNFa-expressing LLC tumors in TNFR-DKO host prompted us to further evaluate the requirement of TNFR signaling in inflammatory cells (i.e bone marrow-derived cells). Therefore, tumor growth was assessed in WT mice receiving bone marrow (BM) transplants from TNFR-DKO mice (referred to as BMTTNFR-DKO mice). Similar to experiments in TNFR-DKO host, LLC line expressing mTNFa isoform, implanted into BMT-TNFR-DKO, did not generate smaller tumors in mice engrafted with TNFR-deficient BM $\left(497.2 \pm 137.6 \mathrm{~mm}^{3}\right)$ as compared with control tumors $\left(387.9 \pm 95.94 \mathrm{~mm}^{3}\right)(P>0.05$; Fig. 3E). Furthermore, we quantified tumor associated myeloid cell populations in these tumors isolated from BMT-TNFRDKO. The overall percentage of myeloid populations in $\mathrm{mTNFa}$-expressing LLC tumors $(7.8 \pm 0.4 \%)$ was similar to control tumors $(7.5 \pm 1.4 \%)(P>0.05$; Fig. $3 \mathrm{~F}$ and $\mathrm{G})$. These data suggested that tumor derived mTNFa significantly reduced myeloid population within the tumor microenvironment. 
Since this effect was abrogated in WT mice transplanted with TNFa receptor deficient BM, it was concluded that intact $\mathrm{TNFa}$ signaling through its receptor in bone marrow derived cells was required for this effect, and that this effect was not mediated by secondary factors from the tumor cells.

\section{mTNFa-derived soluble factors do not affect CD11b+ myeloid cell migration/recruitment}

One possible explanation for the reduction of myeloid cells observed in $\mathrm{mTNFa}$-expressing tumors was that such tumors exhibited reduced expression of necessary signals for myeloid recruitment. Using a modified Boyden chamber assay, we evaluated the ability of conditioned media (CM) from LLC and B16F10 melanoma cell lines expressing various forms of $\mathrm{TNFa}$ to promote migration (i.e. recruitment) of primary murine $\mathrm{CD} 11 \mathrm{~b}+$ myeloid cells. CM from mTNFa did not inhibit migration of CD11b+ as compared to control-CM in both LLC and B16F10 melanoma line (Fig. 4A and Supplementary Fig. S6A). An increase in $\mathrm{CD} 11 \mathrm{~b}+$ myeloid cells migration was observed in CM derived from both IL2spTNFaexpressing LLC ( 1.5-fold; Fig. 4B) and B16F10 line ( 4-fold; Supplementary Fig. S6B). This may be attributed to the presence of TNFa itself, which is known to induce chemotactic response $(19,20)$. These results suggested that the relative paucity of myeloid cells in mTNFa-expressing tumors was likely not due to reduced expression of key cytokines, necessary for myeloid extravasation and migration into the tumor.

We further evaluated the ability of control and mTNFa-expressing LLC tumors to effectively recruit myeloid cell in vivo by adoptive transfer of CFSE labeled CD11b+ into tumor bearing mice. After 18 hours post injection CFSE-positive myeloid cells were quantified in each tumor type by flow analysis of single-cell suspension of tumor digests. The overall number of CFSE-positive cells in $\mathrm{mTNFa}$-expressing LLC tumors $(58 \pm 21)$ was similar to control tumors $(68 \pm 12.57)(P>0.05$; Fig. $4 \mathrm{C}$ and $\mathrm{D})$. These data demonstrate that reduced myeloid cells in $\mathrm{mTNFa}$-expressing tumors was not due to impaired recruitment of circulating cells.

\section{mTNFa induces cell death through apoptosis-independent pathway}

To investigated if the distinct TNFa isoforms exerted cytotoxic effects on myeloid cells, freshly isolated CD11b+ cells (target) were mixed with $1 \%$ paraformaldehyde-fixed B16F10 melanoma cells (effector) expressing empty vector with or without $100 \mathrm{U} / \mathrm{ml}$ recombinant murine TNFa, (FxB16 $6_{\text {cont }}$ or FxB16 $6_{\text {cont }}+\mathrm{rTNFa}$ ) or fixed mTNFa-expressing B16F10 cells (FxB16mTNF) at an effector:target ratio of 10:1. As measured by the MTT assay (Fig. 5A), FxB16 mTNF resulted in more than $60 \pm 29 \%$ cytotoxicity of CD11b+ myeloid cells after 48 hours of incubation, as compared to CD11b+ cells incubated with FxB16 cont $(P<0.005)$. $\mathrm{CD} 11 \mathrm{~b}+$ in the presence of FxB16 $6_{\text {cont }}+\mathrm{rTNFa}$ showed less than $1 \%$ cytotoxicity in compared to control. We assessed the activation of apoptotic pathway as the mechanism of $\mathrm{mTNFa}$-induced myeloid cell death by determining the caspase-3/7 enzymatic activity in $\mathrm{CD} 11 \mathrm{~b}+$ cells. Compared to control, CD11b+ myeloid cells cocultured with FxB16 $6_{\text {cont }}+\mathrm{rTNFa}$ or FxB16 $\mathrm{mTNF}$ did not show any significant increase in the level of caspase $3 / 7$ activity $(P>0.05$, Fig. 5B).

We further assessed the activation of apoptotic pathway in RAW 264.7 cells by determining the level of Bax/Bcl-2of and cleavage/activation of caspase-3 proteins in RAW 264.7. The data suggested that the Bax/Bcl-2 ratio (Fig. 5C) and active-caspase-3 (Fig. 5D) proteins in RAW 264.7 cells treated with both soluble and membrane TNFa had no significant changes when compared to control. Together these findings are indicative of another death pathway independent of apoptosis. 
$\mathrm{NF}-\mathrm{\kappa B}$ is a critical factor in the determination of cell death versus survival and proliferation $(21,22)$. In cases of failed NF- $\times B$ activation, TNFa can induce either programmed cell death or necrosis through complex signal transduction cascades (23). To evaluate whether soluble versus $\mathrm{mTNFa}$ isoforms induced distinct cellular responses via regulation of NF$\kappa B$, we tested NF- $\mathrm{BB}$ activity in RAW 264.7 cells co-cultured with FxB16 $6_{\text {cont }}$,

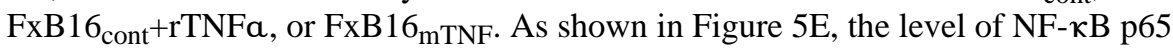
phosphorylation activity in RAW 264.7 cells stimulated with both FxB16 $6_{\text {cont }}+\mathrm{rTNFa}$ and FxB16 mTNF $_{\text {was similar to FxB16 }}$ cont, suggesting that mTNFa isoform did not affect the activity of NF- $\kappa \mathrm{B}$ p65 compared to sTNFa.

\section{mTNFa-induced cell death occurs through induction of ROS}

TNFa can induce cell death by induction of intracellular reactive oxygen spices (ROS)(24, 25). To test the possibility that soluble versus membrane TNFa isoforms induced distinct cellular responses via regulation of intracellular ROS, we evaluated ROS levels in CD11b+ myeloid cells incubated with different TNF isoform by measuring CM-H2DCFDA

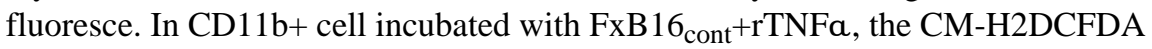
fluorescence did not differ from control, whereas in cells with FxB16 mTNF $_{\text {a }}$ 1.6-fold increase was observed after 8 hours of incubation $(P<0.05$; Fig. 6A). Addition of $\mathrm{N}$-acetylcysteine into cells cultured with $\mathrm{FxB} 16_{\mathrm{mTNF}}$ significantly decreased the intensity of CMH2DCFDA fluorescence indicating decrease in the level of ROS $(P>0.05)$. NAC treatment of FxB16 $6_{\mathrm{mTNF}}$ treated $\mathrm{CD} 11 \mathrm{~b}+$ reduced $\mathrm{mTNFa}$ induced cytotoxicity (FxB16 $6_{\mathrm{mTNF}}$, $61.57 \pm 29.12 \%$ cytotoxicity; FxB16 ${ }_{\mathrm{mTNF}}+\mathrm{NAC}, 10.64 \pm 29.17 \%$ cytotoxicity; $P<0.05$; Fig. $6 \mathrm{~B})$.

In addition we evaluated ROS generation in individual RAW 264.7 by CM-H2DCFDA fluorescent staining assay (26). The fluorescent intensity in RAW 264.7 co-cultured with FxB16 $6_{\text {cont }}+\mathrm{rTNFa}$ was similar to the basal level $(4.6 \pm 3 \%)$. However in the presence of FxB16 $6_{\text {mTNF, }}$ we observed an induction of ROS intensity $(82.5 \pm 15 \%)$ as detected by the presence of green fluorescence staining (Fig. 6C and D). Treatment of RAW 264.7 cocultured with FxB16 mTNF cells supplied with the ROS scavenger N-acetyl-cysteine $\left(\mathrm{FxB} 16_{\mathrm{mTNF}}+\mathrm{NAC}\right)$ diminished $\mathrm{mTNFa}$-induced accumulation of intracellular ROS in RAW 264.7(0.5 $\pm 0.4 \%$; Fig. 6C and D) and led to abolition of mTNFa induced cytotoxicity $\left(\right.$ FxB $16_{\mathrm{mTNF}}, 34 \pm 9 \%$ cytotoxicity; FxB16 $\mathrm{mTNF}^{+\mathrm{NAC}}$, $0.1 \pm 7 \%$ proliferation; $P<0.05$; Fig. $6 \mathrm{E})$.

\section{Relative expression pattern of TNFa/TACE correlates with survival probability in lung cancer patients}

In most studies, the role of TNFa in cancer has only been investigated in murine models or in modified cell lines and to our knowledge the expression level of mTNFa has not been evaluated in human tumors. To extend the relevance of our findings from the murine model to human cancer, we examined 62 tissue cores available in a single human non-small cell lung carcinoma (NSCLC) tissue array containing squamous cell carcinoma, large cell carcinoma, and adenocarcinoma. Using co-immunofluorescent staining analysis with antiTNFa and carcinoma-enriched membrane antigen (EMA) we evaluated the distribution of both degree (high- or low-expressors) and localization (membrane, cytoplamic or both) of $\mathrm{TNFa}$ staining. Forty of 62 individual tumors were positive for TNFa expression. Among 40 tumors, expressing either high or low TNFa, we detected tumors presenting high levels of membrane-localized TNFa, tumors presenting high cytoplasmic TNFa (i.e. tumors with higher expression of sTNFa) or tumors with cytoplasmic and membrane-localized TNFa. Eighteen of the 40 tumors (45\%) were high expresser with $27.8 \%$ cytoplasmic localization, $16.7 \%$ localized on the membrane and $55.5 \%$ were positive for both membrane and cytoplasmic TNFa. Twenty two (65\%) showed low expression of TNFa with $18.3 \%$ 
cytoplasmic, 31.8\% membrane and 50\% with both membrane and cytoplasmic (Fig. 7A). These data are the first evidence for the existence of $\mathrm{mTNFa}$ in human tumors and that its level varies significantly from patient to patient. Moreover, its level and localization varies significantly from patient to patient, which is likely an important consideration in predicted therapeutic response to anti-TNF agents based on our pre-clinical observations.

To provide further evidence that human tumors exhibit varying expression of TNFa isoforms, the expression of sTNFa was determined by ELISA of CM and the expression of mTNFa was evaluated by immunoblot analysis of cell membrane fraction. The analysis showed significant variation in the relative expression of membrane versus soluble TNFa among different human lung cancer-derived cell lines (Fig. 7B).

Next we investigated the possible association of sTNFa versus mTNFa ratio with patient outcome (17). It has been shown that there is a positive correlation between TACE surface expression and TNFa cleavage. Upregulation of TACE protein has also been shown to be associated with a decline in mTNFa level and increased soluble level and vice versa (27). Using publicly accessible NSCLC microarray database ( $\mathrm{n}=442$ patients), we divided the gene expression data into four groups. The first two groups featured low TNFa gene expression and low or high TACE. The third and fourth groups demonstrated high TNFa with either low or high TACE. Over all higher TACE level was significantly correlated to lower survival probability. Expression of high TNFa/low TACE - representing tumors with high mTNFa:sTNFa relative expression - was associated with longer survival than expression of high TNFa/high TACE — representing tumors with low mTNFa:sTNFa relative expression (log rank $P=0.035$; Fig. 7C).

\section{DISCUSSION}

Data from both experimental and human cancers have identified TNFa as key cytokine modulating tumor progression, yet its effects are incompletely understood. In murine models, deletion or inhibition of TNFa reduces the incidence of cancer formation and even increases resistance to chemically induced carcinogenesis of the skin $(28,29)$. Consistent with this, there was a positive correlation between level of TNFa expression and tumor grade in ovarian tumors (30). On the other hand, anti-tumorigenic properties of TNFa are also well-documented. In a study by Boldrini et. al, assessment of TNFa expression in 61 NSCLC samples demonstrated expression of TNFa in $45.9 \%$ of cases and directly correlated with a better clinical outcome (31).

Many soluble proteins such as TNFa are originally expressed as a membrane-bound form and then processed to a secretory form through proteolytic cleavage. Some of these proteins such as Fas ligand, a member of TNFa super family, have been described to have distinct biological effects on disease process as a membrane isoform when compared to the soluble isoform (32). In this study we sought to better understand the role of different TNFa isoforms in the modulation of tumor progression and to determine if some of the reported opposing effects can be attributed to distinct effects of these isoforms.

We generated tumor cell lines expressing either uncleavable mTNFa or sTNFa. Subcutaneous implantation of mTNFa expressing LLC and B16F10 cancer cell lines resulted in significantly smaller tumors which was not the result of impaired angiogenesis or reduced tumor cell proliferation but was driven by components of the host derived cells. This idea was further strengthened by significant reduction of tumor associated myeloid cell content in $\mathrm{mTNFa}$-expressing tumors which were restored in tumor cells transplanted in TNFR-DKO mice. Numerous studies have shown critical roles for tumor-associated stromal cells, specifically, bone marrow-derived myeloid cells, in tumor growth $(33,34)$. Upon 
activation by cancer cells, tumor-associated macrophages can release growth factors, cytokines and inflammatory mediators that may facilitate cancer cell invasion, migration, angiogenesis, tumor progression or metastasis (35-37). Furthermore, systemic depletion (38) or inhibition (39) of tumor associated myeloid cells migration into the tumor has shown to significantly reduce tumor growth. In light of our findings, it would be of great interest to determine the precise role of myeloid cells in mTNFa-mediated tumor growth.

Our study revealed that tumor cell expression of the membrane isoform of TNFa resulted in tumor associated myeloid cell death through increased ROS production. It has been shown that $\mathrm{TNFa}$ has the ability to induce necrotic cell death by utilizing death domain-containing adaptor proteins such as RIP1, TRADD and FADD upon TNFR activation. Once recruited to the TNFR death domain further downstream events lead to ROS generation and cell death (40-42). Multiple pathways have been shown to lead to ROS generation upon TNFR activation $(24,43)$. Necrotic cell death induced by TNFR has been associated with generation of ROS derived from either mitochondrial or non-mitochondrial sources $(43,44)$. Mitochondrial complex I-mediated generation of ROS has been linked to direct activation by TNFR and ceramide mediated activation $(40,41)$. In a study by Kim et al., TNFR was reported as an activator of Nox1 NADPH oxidase complex in a TRADD-and RIP1dependent recruitment (45). Our findings suggest that the membrane form of TNFa is very efficient at stimulating ROS generation and initiating necrotic cell death. This could be due to the ability of mTNF to recruit death domain-containing adaptor proteins more efficiently or mTNFa activates a pathway that is more efficient in ROS generation. The mechanistic pathway(s) which leads to mTNFa induced ROS generation requires further investigation.

To our knowledge there has not been any study evaluating the relative expression of soluble and membrane TNFa during tumor progression in human cancer, including analyses designed to determine if there is any correlation between the level of sTNFa versus mTNFa and the cancer outcome. Here, in this study our in vivo tissue array staining and in vitro assessment of soluble and membrane TNFa expression in human NSCLC cell lines showed that the ratio of soluble to membrane TNFa varies among different tumor cell types. Furthermore, we verified this by immunofluorescence staining of tumor section for TNFa. The fact that mTNFa is present in tumor and at different levels and subcellular localization may provides important clues to divergent outcomes seen in TNFa positive tumor phenotype seen in different patients.

As it previously described, in order to generate sTNFa, the membrane associated TNFa is cleaved through proteolytic activity of TACE. Although it has been suggested that other proteinases are capable of TNFa cleavage it has been shown that TACE has the highest affinity for TNFa ectodomain shedding among the other known substrate (27). Level of TACE present on the surface of the membrane has been inversely correlated with the level of membrane associated TNFa and inhibition of TACE by MMP inhibitors has demonstrated a transient increase in mTNFa surface expression $(27,46)$. These studies suggest that the regulation of TACE activity and subsequent alteration of the sTNFa to mTNFa ratio could have a great impact on tumor growth. The association between higher TACE and higher TNFa gene expression in NSCLC and decreased survival further confirms the importance of different TNFa isoforms availability on tumor regulation.

Recently several Phase I/II clinical trials have been undertaken with TNFa antagonists in cancer patients (47-49). In these clinical trials, TNFa antagonist treatment resulted in a period of disease stabilization in only $20 \%$ of the patients with advanced cancer. It is suggested that in order to take this forward, we need to identify those patients who are most likely to benefit from TNFa antagonist treatment. Perhaps determining the predominant 
form of TNFa expressed by tumor in these patients would be beneficial for a more effective treatment with TNFa inhibitors which can block both soluble and membrane isoforms.

In summary, we demonstrate that $\mathrm{TNFa}$ membrane versus soluble isoforms have opposing effects on cancer growth. Expression of both forms of TNFa in NSCLCs indicates that this finding is relevant to human malignancies and that isoform analysis should be applied to identify candidates for which anti-TNFa agents are likely to be beneficial versus detrimental.

\section{Supplementary Material}

Refer to Web version on PubMed Central for supplementary material.

\section{Acknowledgments}

Financial support: This work was supported by funding from the NIH (R01-HL088424) to PPY, Veterans Affairs Merit Award to PPY, Vanderbilt University CTSA Grant (UL1 RR024975-01 from NCRR/NIH) to PPY, SPORE in lung cancer (NCI CA 90949) to PPM, and IBVS training grant (5 T32 HL069765) to SA.

\section{GRANT SUPPORT}

This work was supported by funding from the NIH (R01-HL088424) to PPY, Veterans Affairs Merit Award to PPY, Vanderbilt University CTSA Grant (UL1 RR024975-01 from NCRR/NIH) to PPY, SPORE in lung cancer (NCI CA 90949) to PPM, and IBVS training grant (5 T32 HL069765) to SA.

\section{References}

1. Bozcuk H, Uslu G, Samur M, et al. Tumour necrosis factor-alpha, interleukin-6, and fasting serum insulin correlate with clinical outcome in metastatic breast cancer patients treated with chemotherapy. Cytokine. 2004; 27:58-65. [PubMed: 15242694]

2. Ferrajoli A, Keating MJ, Manshouri T, et al. The clinical significance of tumor necrosis factor-alpha plasma level in patients having chronic lymphocytic leukemia. Blood. 2002; 100:1215-9. [PubMed: 12149200]

3. Michalaki V, Syrigos K, Charles P, Waxman J. Serum levels of IL-6 and TNF-alpha correlate with clinicopathological features and patient survival in patients with prostate cancer. Br J Cancer. 2004; 90:2312-6. [PubMed: 15150588]

4. Pfitzenmaier J, Vessella R, Higano CS, Noteboom JL, Wallace D Jr, Corey E. Elevation of cytokine levels in cachectic patients with prostate carcinoma. Cancer. 2003; 97:1211-6. [PubMed: 12599227]

5. Yoshida N, Ikemoto S, Narita K, et al. Interleukin-6, tumour necrosis factor alpha and interleukin-1beta in patients with renal cell carcinoma. Br J Cancer. 2002; 86:1396-400. [PubMed: 11986770]

6. Balkwill F. TNF-alpha in promotion and progression of cancer. Cancer Metastasis Rev. 2006; 25:409-16. [PubMed: 16951987]

7. Balkwill F, Charles KA, Mantovani A. Smoldering and polarized inflammation in the initiation and promotion of malignant disease. Cancer Cell. 2005; 7:211-7. [PubMed: 15766659]

8. Li B, Vincent A, Cates J, Brantley-Sieders DM, Polk DB, Young PP. Low levels of tumor necrosis factor alpha increase tumor growth by inducing an endothelial phenotype of monocytes recruited to the tumor site. Cancer Res. 2009; 69:338-48. [PubMed: 19118019]

9. Chakravarty EF, Michaud K, Wolfe F. Skin cancer, rheumatoid arthritis, and tumor necrosis factor inhibitors. J Rheumatol. 2005; 32:2130-5. [PubMed: 16265690]

10. Brown SL, Greene MH, Gershon SK, Edwards ET, Braun MM. Tumor necrosis factor antagonist therapy and lymphoma development: twenty-six cases reported to the Food and Drug Administration. Arthritis Rheum. 2002; 46:3151-8. [PubMed: 12483718]

11. Larkin JM, Ferguson TR, Pickering LM, et al. A phase I/II trial of sorafenib and infliximab in advanced renal cell carcinoma. Br J Cancer. 103:1149-53. [PubMed: 20842130] 
12. Kriegler M, Perez C, DeFay K, Albert I, Lu SD. A novel form of TNF/cachectin is a cell surface cytotoxic transmembrane protein: ramifications for the complex physiology of TNF. Cell. 1988; 53:45-53. [PubMed: 3349526]

13. Diwan A, Dibbs Z, Nemoto S, et al. Targeted overexpression of noncleavable and secreted forms of tumor necrosis factor provokes disparate cardiac phenotypes. Circulation. 2004; 109:262-8. [PubMed: 14699008]

14. Dibbs ZI, Diwan A, Nemoto S, et al. Targeted overexpression of transmembrane tumor necrosis factor provokes a concentric cardiac hypertrophic phenotype. Circulation. 2003; 108:1002-8. [PubMed: 12912811]

15. Parry SL, Sebbag M, Feldmann M, Brennan FM. Contact with T cells modulates monocyte IL-10 production: role of T cell membrane TNF-alpha. J Immunol. 1997; 158:3673-81. [PubMed: 9103430]

16. Siegel R, Naishadham D, Jemal A. Cancer statistics, 2012. CA Cancer J Clin. 2012; 62:10-29. [PubMed: 22237781]

17. Shedden K, Taylor JM, Enkemann SA, et al. Gene expression-based survival prediction in lung adenocarcinoma: a multi-site, blinded validation study. Nat Med. 2008; 14:822-7. [PubMed: 18641660]

18. de Jong JP, Voerman JS, van der Sluijs-Gelling AJ, Willemsen R, Ploemacher RE. A monoclonal antibody (ER-HR3) against murine macrophages. I. Ontogeny, distribution and enzyme histochemical characterization of ER-HR3-positive cells. Cell Tissue Res. 1994; 275:567-76. [PubMed: 8137402]

19. de Jong AL, Green DM, Trial JA, Birdsall HH. Focal effects of mononuclear leukocyte transendothelial migration: TNF-alpha production by migrating monocytes promotes subsequent migration of lymphocytes. J Leukoc Biol. 1996; 60:129-36. [PubMed: 8699117]

20. Torrente Y, El Fahime E, Caron NJ, et al. Tumor necrosis factor-alpha (TNF-alpha) stimulates chemotactic response in mouse myogenic cells. Cell Transplant. 2003; 12:91-100. [PubMed: 12693669]

21. Senftleben U, Karin M. The IKK/NF-kappaB pathway. Crit Care Med. 2002; 30:S18-S26.

22. Karin M, Lin A. NF-kappaB at the crossroads of life and death. Nat Immunol. 2002; 3:221-7. [PubMed: 11875461]

23. Gupta S. A decision between life and death during TNF-alpha-induced signaling. J Clin Immunol. 2002; 22:185-94. [PubMed: 12148593]

24. Corda S, Laplace C, Vicaut E, Duranteau J. Rapid reactive oxygen species production by mitochondria in endothelial cells exposed to tumor necrosis factor-alpha is mediated by ceramide. Am J Respir Cell Mol Biol. 2001; 24:762-8. [PubMed: 11415943]

25. Deshpande SS, Angkeow P, Huang J, Ozaki M, Irani K. Rac1 inhibits TNF-alpha-induced endothelial cell apoptosis: dual regulation by reactive oxygen species. FASEB J. 2000; 14:170514. [PubMed: 10973919]

26. Kim JH, Lee BC, Sim GS, et al. The isolation and antioxidative effects of vitexin from Acer palmatum. Arch Pharm Res. 2005; 28:195-202. [PubMed: 15789751]

27. Armstrong L, Godinho SI, Uppington KM, Whittington HA, Millar AB. Contribution of TNFalpha converting enzyme and proteinase-3 to TNF-alpha processing in human alveolar macrophages. Am J Respir Cell Mol Biol. 2006; 34:219-25. [PubMed: 16210695]

28. Moore RJ, Owens DM, Stamp G, et al. Mice deficient in tumor necrosis factor-alpha are resistant to skin carcinogenesis. Nat Med. 1999; 5:828-31. [PubMed: 10395330]

29. Arnott CH, Scott KA, Moore RJ, Robinson SC, Thompson RG, Balkwill FR. Expression of both TNF-alpha receptor subtypes is essential for optimal skin tumour development. Oncogene. 2004; 23:1902-10. [PubMed: 14661063]

30. Naylor MS, Stamp GW, Foulkes WD, Eccles D, Balkwill FR. Tumor necrosis factor and its receptors in human ovarian cancer. Potential role in disease progression. J Clin Invest. 1993; 91:2194-206. [PubMed: 8387543]

31. Boldrini L, Calcinai A, Samaritani E, et al. Tumour necrosis factor-alpha and transforming growth factor-beta are significantly associated with better prognosis in non-small cell lung carcinoma: 
putative relation with BCL-2-mediated neovascularization. Br J Cancer. 2000; 83:480-6. [PubMed: 10945495]

32. LAOR, Tai L, Lee L, et al. Membrane-bound Fas ligand only is essential for Fas-induced apoptosis. Nature. 2009; 461:659-63. [PubMed: 19794494]

33. De Palma M, Venneri MA, Galli R, et al. Tie2 identifies a hematopoietic lineage of proangiogenic monocytes required for tumor vessel formation and a mesenchymal population of pericyte progenitors. Cancer Cell. 2005; 8:211-26. [PubMed: 16169466]

34. Shojaei F, Zhong C, Wu X, Yu L, Ferrara N. Role of myeloid cells in tumor angiogenesis and growth. Trends Cell Biol. 2008; 18:372-8. [PubMed: 18614368]

35. Condeelis J, Pollard JW. Macrophages: obligate partners for tumor cell migration, invasion, and metastasis. Cell. 2006; 124:263-6. [PubMed: 16439202]

36. White ES, Strom SR, Wys NL, Arenberg DA. Non-small cell lung cancer cells induce monocytes to increase expression of angiogenic activity. J Immunol. 2001; 166:7549-55. [PubMed: 11390510]

37. Wang FQ, So J, Reierstad S, Fishman DA. Matrilysin (MMP-7) promotes invasion of ovarian cancer cells by activation of progelatinase. Int J Cancer. 2005; 114:19-31. [PubMed: 15523695]

38. Zeisberger SM, Odermatt B, Marty C, Zehnder-Fjallman AHM, Ballmer-Hofer K, Schwendener RA. Clodronate-liposome-mediated depletion of tumour-associated macrophages: a new and highly effective antiangiogenic therapy approach. British Journal of Cancer. 2006; 95:272-81. [PubMed: 16832418]

39. Allavena P, Signorelli M, Chieppa M, et al. Anti-inflammatory properties of the novel antitumor agent yondelis (Trabectedin): Inhibition of macrophage differentiation and cytokine production. Cancer Research. 2005; 65:2964-71. [PubMed: 15805300]

40. Festjens N, Vanden Berghe T, Vandenabeele P. Necrosis, a well-orchestrated form of cell demise: signalling cascades, important mediators and concomitant immune response. Biochim Biophys Acta. 2006; 1757:1371-87. [PubMed: 16950166]

41. Morgan MJ, Kim YS, Liu ZG. TNFalpha and reactive oxygen species in necrotic cell death. Cell Res. 2008; 18:343-9. [PubMed: 18301379]

42. Lin Y, Choksi S, Shen HM, et al. Tumor necrosis factor-induced nonapoptotic cell death requires receptor-interacting protein-mediated cellular reactive oxygen species accumulation. J Biol Chem. 2004; 279:10822-8. [PubMed: 14701813]

43. Vanden Berghe T, Declercq W, Vandenabeele P. NADPH oxidases: new players in TNF-induced necrotic cell death. Mol Cell. 2007; 26:769-71. [PubMed: 17588511]

44. Schwandner R, Wiegmann K, Bernardo K, Kreder D, Kronke M. TNF receptor death domainassociated proteins TRADD and FADD signal activation of acid sphingomyelinase. J Biol Chem. 1998; 273:5916-22. [PubMed: 9488730]

45. Kim S, Takahashi H, Lin W-W, et al. Carcinoma-produced factors activate myeloid cells through TLR2 to stimulate metastasis. Nature. 2009; 457:102-6. [PubMed: 19122641]

46. Solomon KA, Covington MB, DeCicco CP, Newton RC. The fate of pro-TNF-alpha following inhibition of metalloprotease-dependent processing to soluble TNF-alpha in human monocytes. $\mathbf{J}$ Immunol. 1997; 159:4524-31. [PubMed: 9379053]

47. Brown ER, Charles KA, Hoare SA, et al. A clinical study assessing the tolerability and biological effects of infliximab, a TNF-alpha inhibitor, in patients with advanced cancer. Ann Oncol. 2008; 19:1340-6. [PubMed: 18325912]

48. Harrison ML, Obermueller E, Maisey NR, et al. Tumor necrosis factor alpha as a new target for renal cell carcinoma: two sequential phase II trials of infliximab at standard and high dose. J Clin Oncol. 2007; 25:4542-9. [PubMed: 17925549]

49. Madhusudan S, Foster M, Muthuramalingam SR, et al. A phase II study of etanercept (Enbrel), a tumor necrosis factor alpha inhibitor in patients with metastatic breast cancer. Clin Cancer Res. 2004; 10:6528-34. [PubMed: 15475440] 


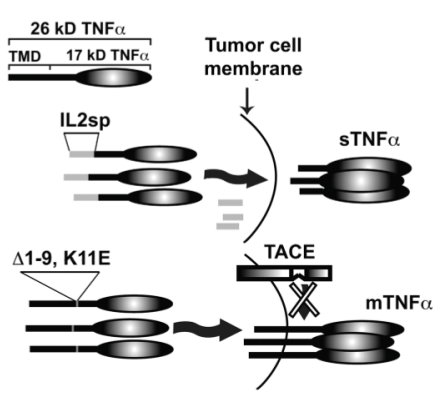

C

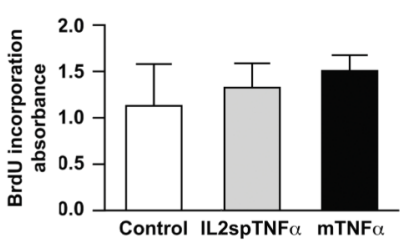

B

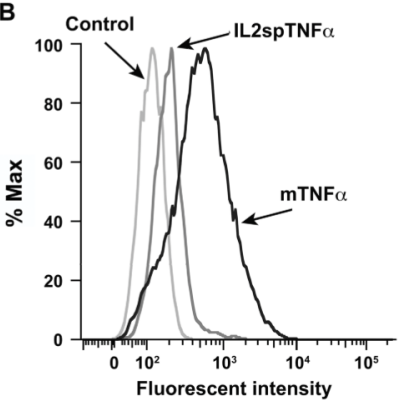

D

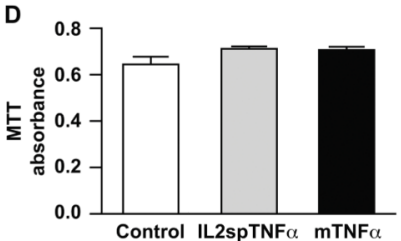

E

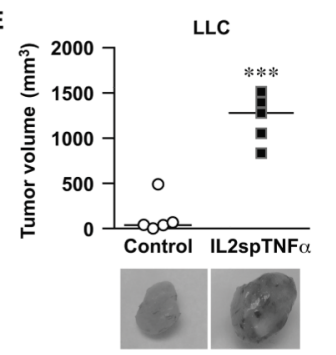

$\mathbf{F}$

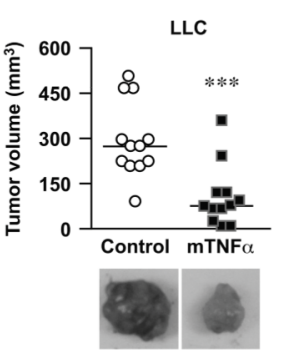

G

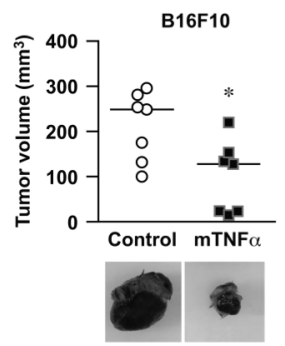

Figure 1. mTNFa-expressing tumor cells demonstrate delayed tumor growth

(A) Schematic representation of TNFa mutant which has the region coding for the TNFa transmembrane domain (TMD) replaced with region coding for interleukin-2 (IL-2) signal peptide to generate soluble TNFa (sTNFa) and TNFa lacking TACE cleavage site $(\Delta 1-9$, $\mathrm{K} 11 \mathrm{E})$ to generate membrane TNFa (mTNFa). (B) Expression of transmembrane TNFa on the surface of LLC tumor cells transduced with empty vector (control), IL2spTNFa or mTNFa vectors was analyzed by flow cytometery. (C and D) Proliferation rate and the viability of transduced tumor cells were determined by BrdU and MTT labeling assays respectively. All cell lines showed no significant difference in proliferation or viability. Data is representative of three independent experiments expressed as the mean \pm SEM. (E-G) In vivo growth of tumor cells transduced with control vector was compared to LLC lines expressing IL2spTNFa (E), or mTNFa (F), and B16F10 expressing mTNFa (G), by subcutaneous implantation in WT bl/6 mice for 14 days. Each point represents an individual animal and the horizontal bar is the Mean. $* P<0.05$, *** $P<0.0005$, Student's $t$-test. Photomicrograph of each tumor is shown with each experimental group. 
A

Control
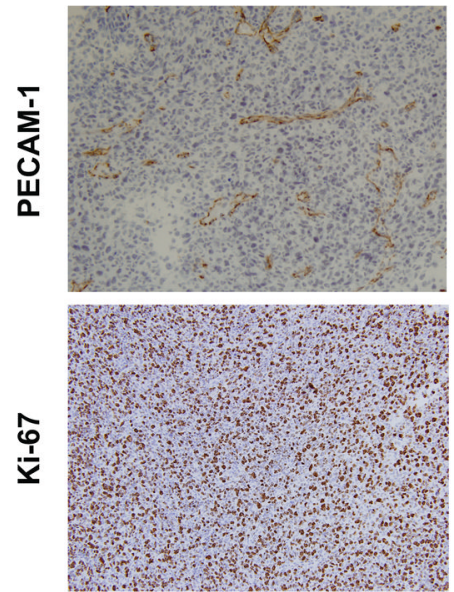

IL2spTNF $\alpha$
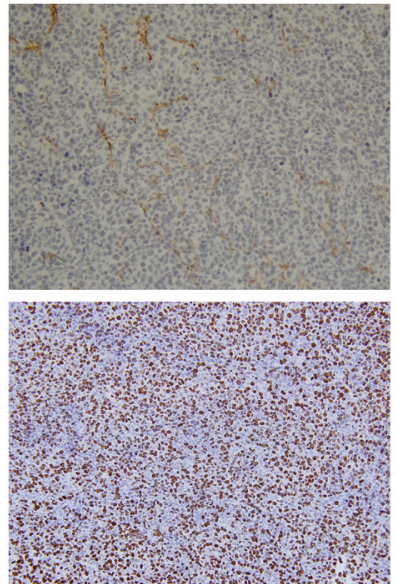

$\operatorname{mTNF} \alpha$
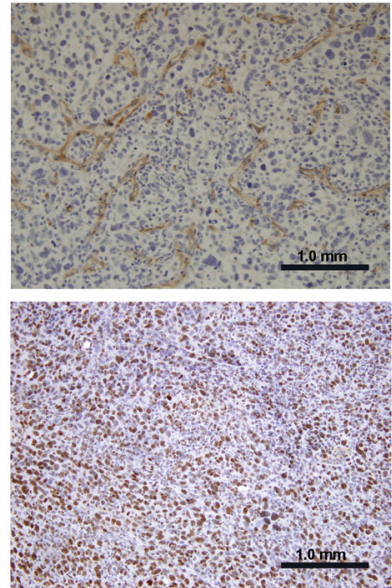
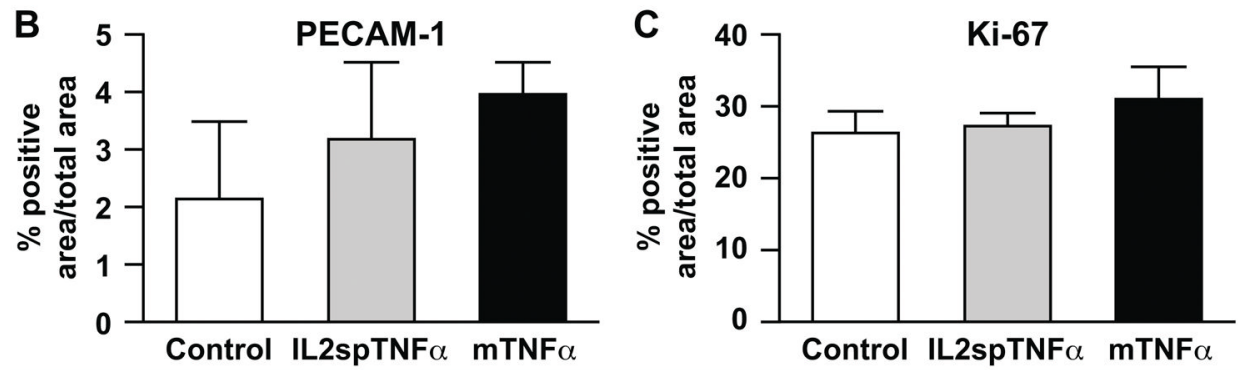

Figure 2. Expression of $\mathrm{mTNFa}$ does not affect tumor proliferation or vascularity in vivo (A) Representative sections of LLC tumors transduced with control, IL2spTNFa and mTNFa constructs were analyzed by immunohistochemistry for PECAM-1 or Ki-67 staining to define vascularity or proliferation, respectively. (B and C) Percentage of PECAM-1-positive (B) or Ki-67-positive area (C) in control, IL2spTNFa and mTNFa in LLC tumors was quantitated. There was no significant difference between the cohorts for either PECAM-1-positive or Ki-67-positive cells ( $P>0.05)$, 1-way ANOVA with Tukey's post-test. 

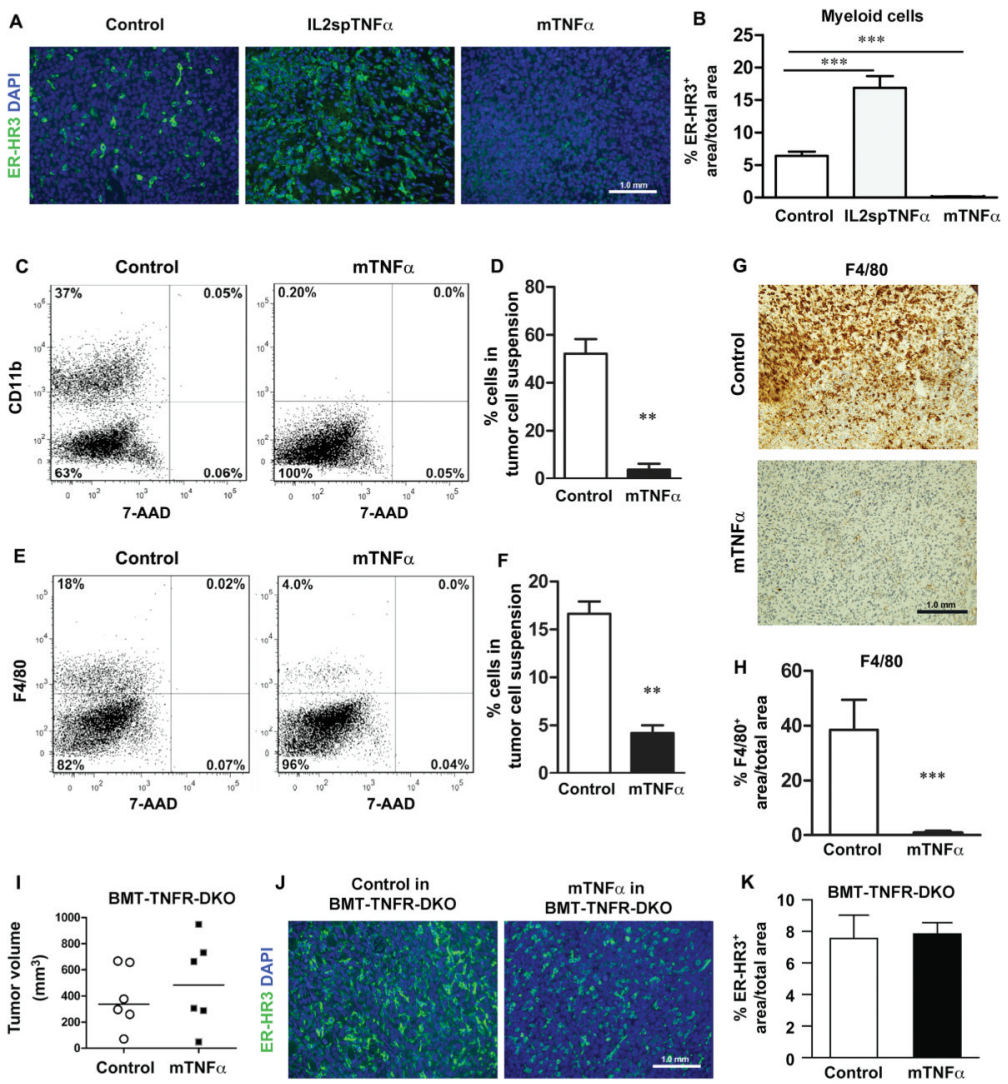

Figure 3. mTNFa-expressing tumors are devoid of tumor-associated myeloid cells (A) ER-HR3 staining of LLC tumor cells, expressing various TNFa isoforms. Control (left), IL2spTNFa (middle), and mTNFa (right) LLC tumor sections from wild-type bl/6 were stained with ER-HR3 myeloid markers (green). (B) Percentage of ER-HR3-positive cells in LLC tumors transduced with control or different of TNFa isoforms was quantitated. There was a significant decrease in the number of ER-HR3-positive cells in LLC tumors expressing $\mathrm{mTNFa}$ isoform compared to control tumors. (C and E) Representative flow cytometric analysis of CD11b- and F4/80-postitive population in LLC tumor cell suspension. Dot plots show CD11b/7-AAD (C) and F4/80/7-AAD (E) from one representative animal for each group. (D and F) Percentage of CD11b- and F4/80-positive cells were quantitated in control and mTNFa tumor cell suspensions. (G) Representative sections of control and mTNFa-transfected LLC tumors were analyzed by immunohistochemistry for F4/80+ macrophages. (H) Number of F4/80-postivie cells in control and mTNFa in LLC tumors was quantitated. (I) Control and mTNFa-expressing LLC tumor cells were implanted subcutaneously in WT bl/6 mice received bone marrow (BM) transplant from TNFa receptors $1 / 2$ knockout donor (BMT-TNFR-DKO mice) for 14 days. The mean is shown for each group ( $\mathrm{n}=6$ animals). (J) Representative ER-HR3 immunofluorescence staining from control and mTNFa-transduced tumors. (K) Percentage of ER-HR3-positive cells in control and mTNFa-expressing LLC tumors from WT mice with BMT from DRKO donor was quantitated. There was no significant difference between the cohorts for ER-HR3-positive cells $(\mathrm{n}=3)$. Data are presented as mean $\pm \mathrm{SEM}, * * P<0.005$, $* * * P<0.0005$; Student's $t$-test. 
A

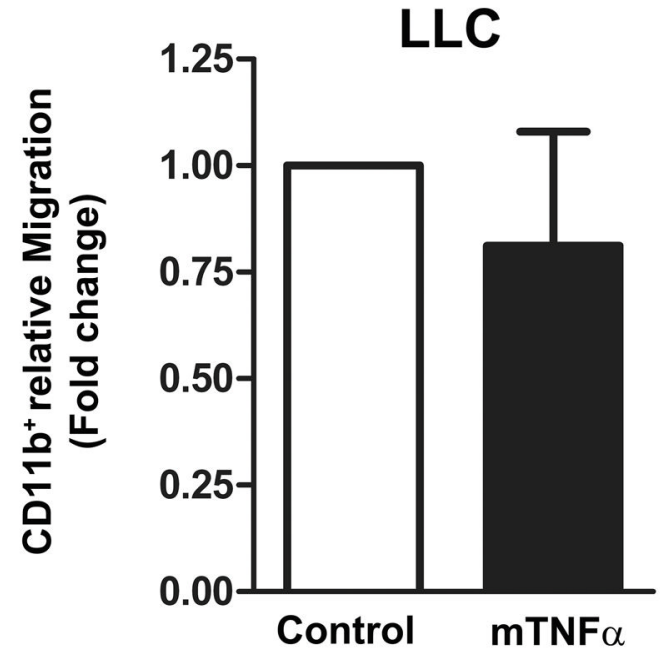

B

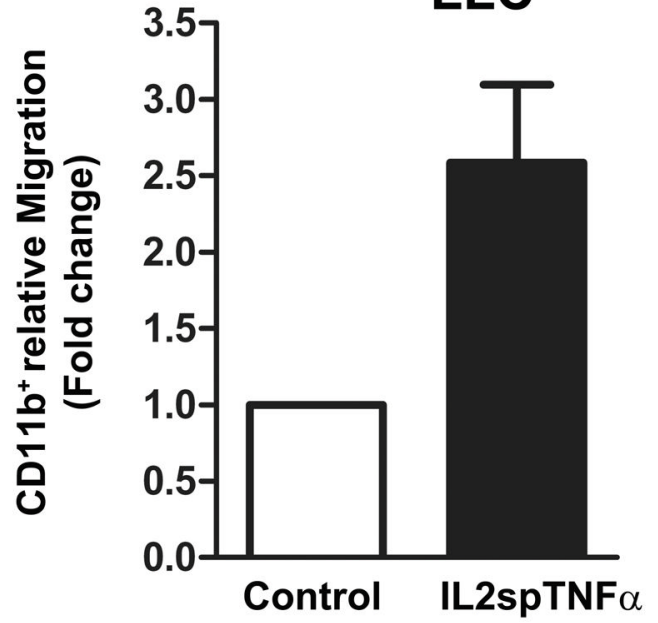

C

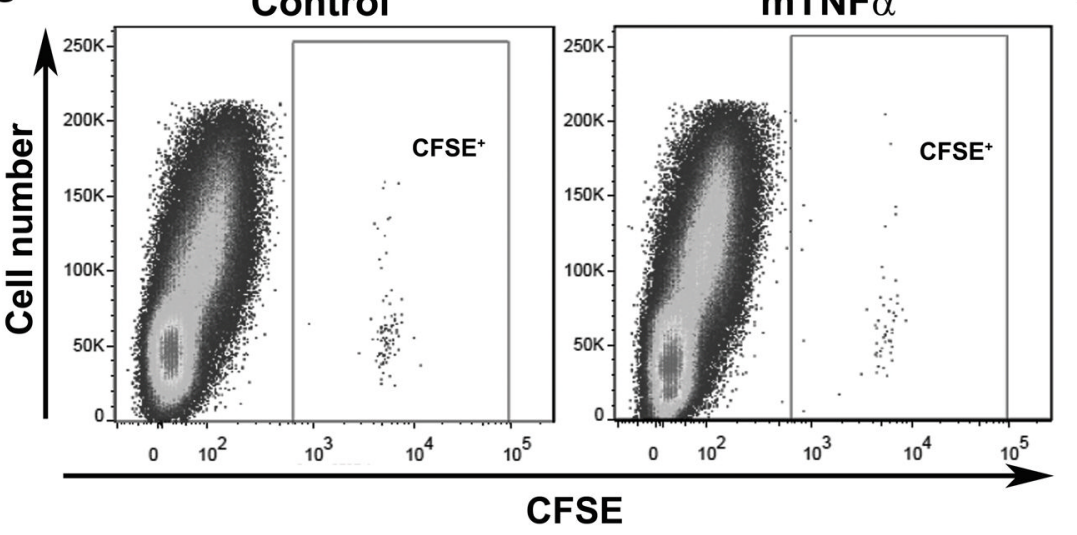

D

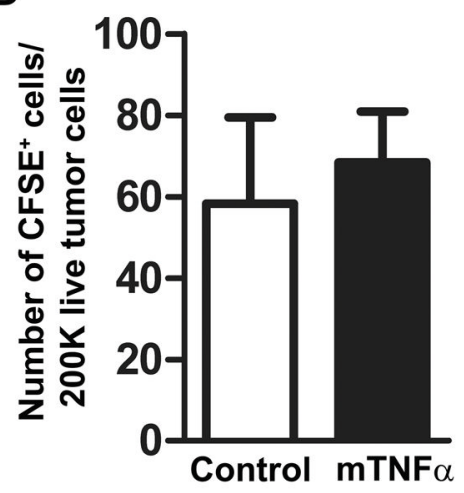

Figure 4. Soluble factors derived from mTNFa do not affect the rate of CD11b+ myeloid cell migration compared to control

(A and B) Transwell migration assay of primary CD11b+ cells treated with conditioned media derived from LLC tumor cells transduced with control/mTNFa (A) or cotnrol/ IL2spTNFa (B) constructs. Data presents the mean \pm SEM. (C) Representative flow cytometric analysis of CFSE-positive cells presented in LLC tumor suspension expressing either control (left) or mTNFa (right) isoform. (D) Quantification of CFSE-positive cells detected in a given number of tumor suspension $(n=3$ for each tumor type). Data are presented as mean \pm SEM, $P>0.05$. 
A

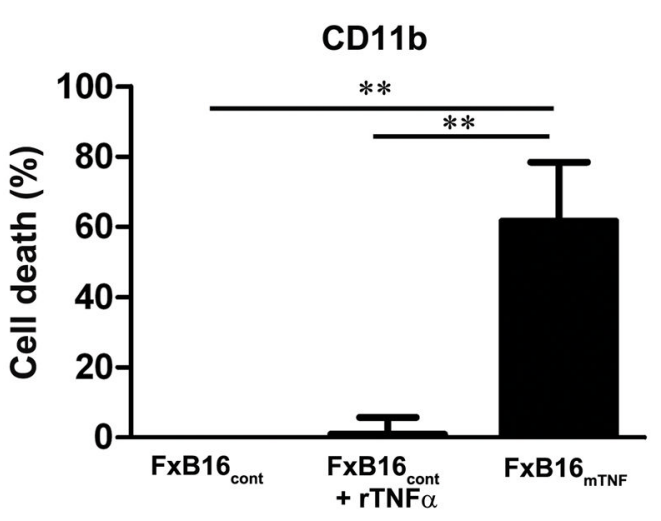

B

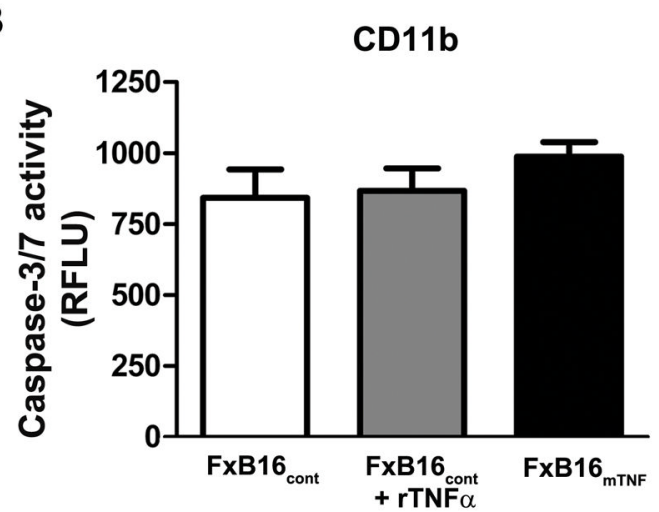

C

RAW 264.7 co-cultured with:
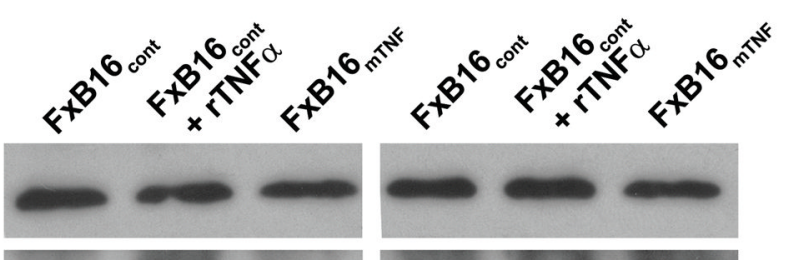

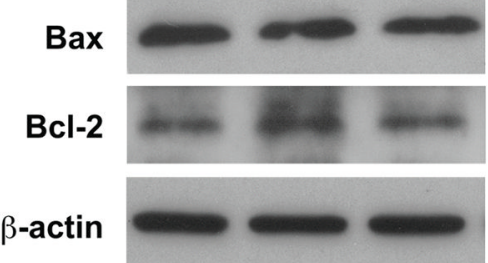

6 hours

D

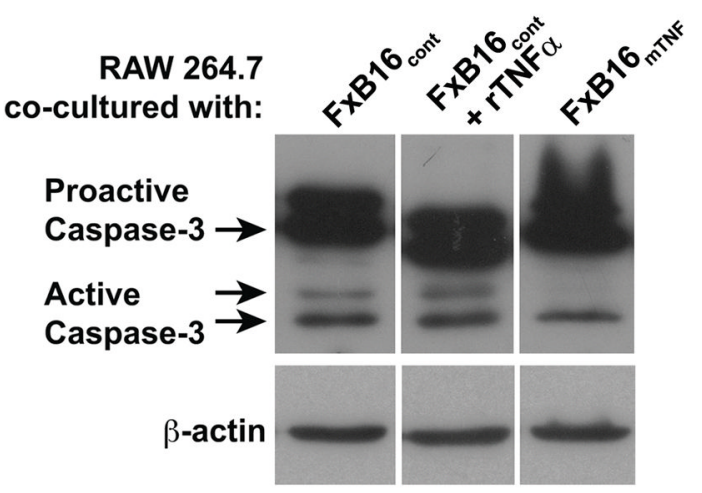

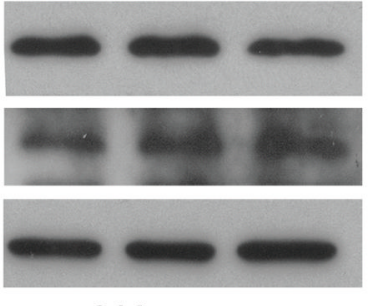

24 hours
E

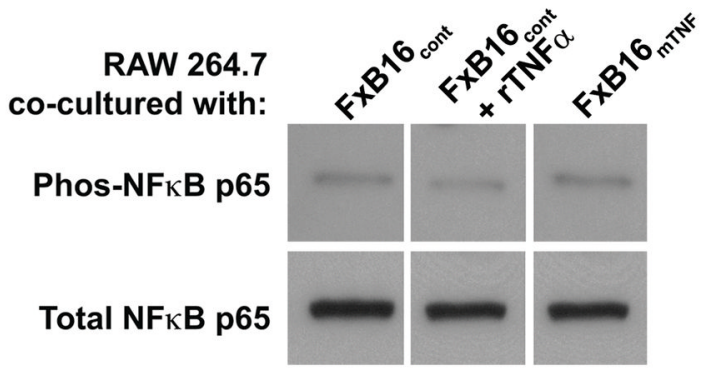

Figure 5. mTNFa induces cell death through apoptosis-independent pathway

(A) Cytotoxic effect of sTNFa and mTNFa on CD11b+ cells measured by MTT assay. (B) Caspase-3/7 activity in CD11b+ cocultured with Paraformaldehyde-fixed control (FxB16 cont ), control+rTNFa (FxB16cont+TNFa), or mTNFa (FxB16 mTNF$_{\text {) }}$. (C-E) Kinetics of Bax/Bcl-2, caspase-3 and NF- $\kappa$ B activation in RAW 264.7 after incubation with cancer cells transduced with various TNFa constructs. FxB16 $6_{\text {cont, }}$ FxB16 $6_{\text {cont }}+$ TNFa, or

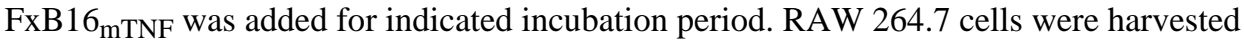
and total cellular protein was analyzed for Bax/Bcl-2 ratio $(\mathbf{C})$, activated caspase-3 (D), and total and phopho- NF- $\kappa$ B p65 (E). Immunoblot analysis showed no differences in Bax/Bcl-2 ratio or caspase- 3 and NF- $\kappa \mathrm{B}$ pathway activation with different $\mathrm{TNFa}$ isoforms compared to control. ** $P<0.05,1$-way ANOVA with Tukey's post-test. 
A

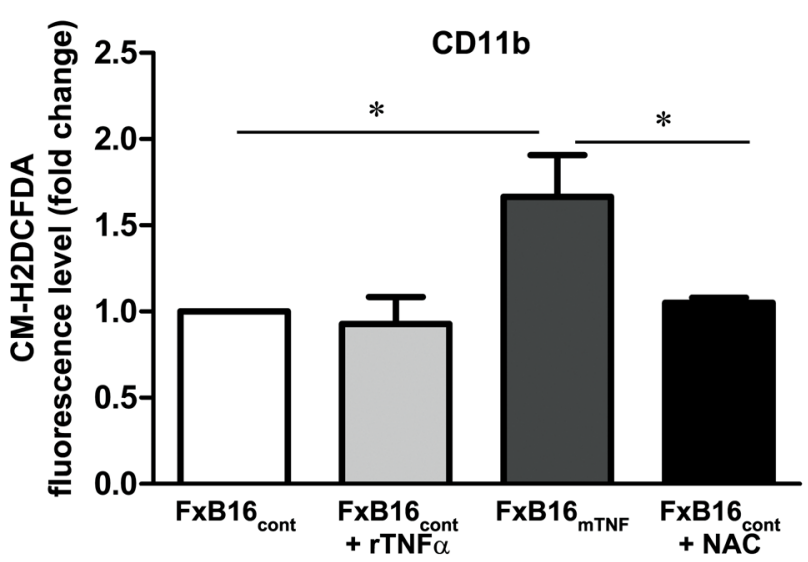

C
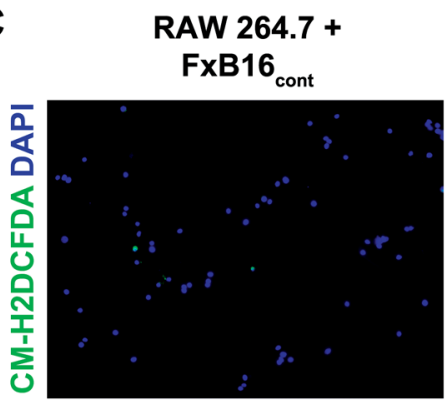

D

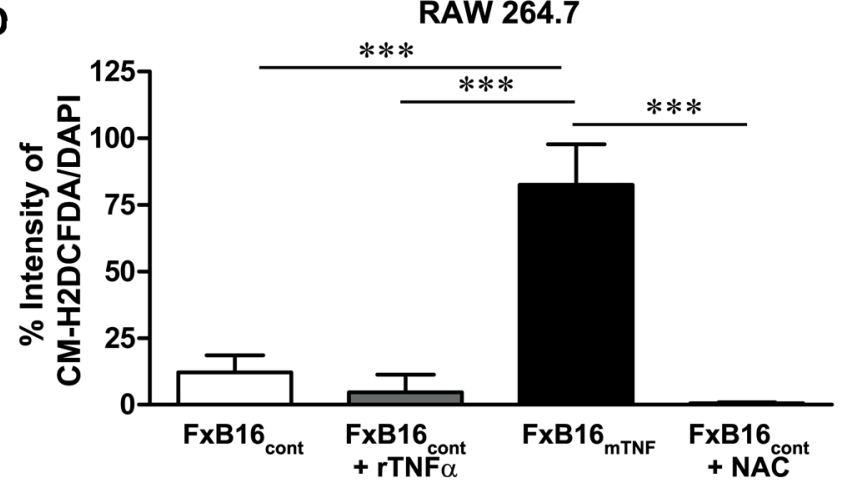

RAW $264.7+$ FXB16 $_{\text {cont }}+$ rTNF $\alpha$

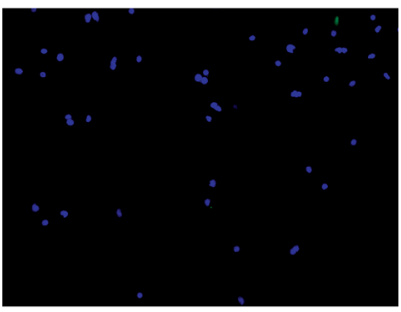

B

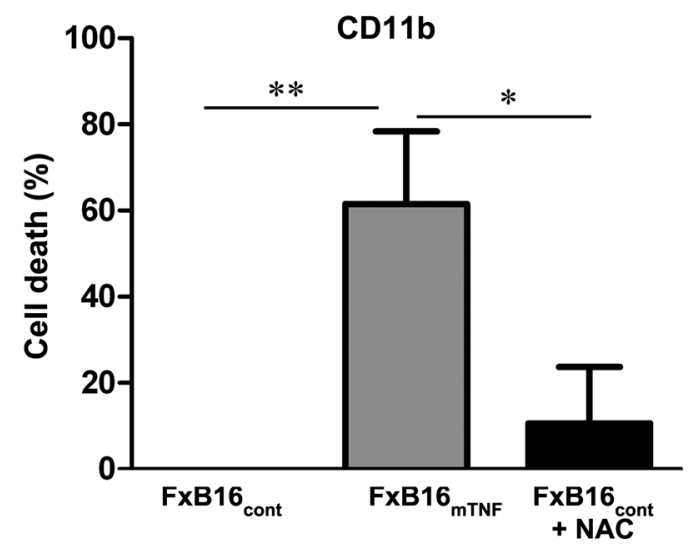

E

RAW 264.7

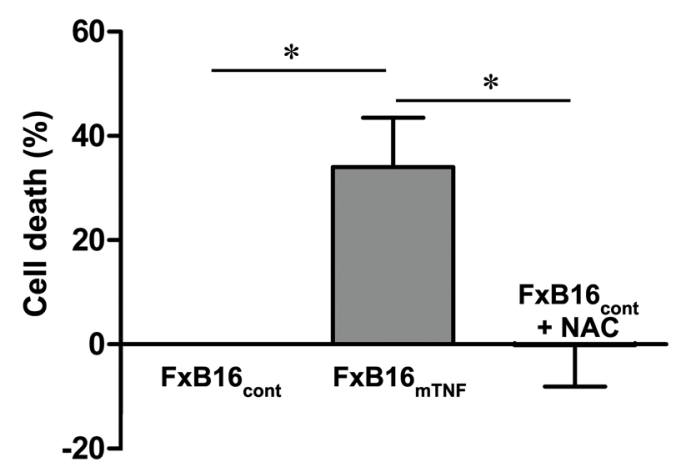

Figure 6. mTNFa-induced cell death occurs through induction of ROS

(A) Effects of various TNFa isoforms on intracellular ROS generation in CD11b+ cells. Cells were labeled with ROS detection reagent, CM-H2DCFDA, and incubated with FxB16 $6_{\text {cont }}$, FxB16 $6_{\text {cont }}+\mathrm{TNFa}$, or FxB16 $6_{\mathrm{mTNF}}, \mathrm{FxB}_{16} 6_{\mathrm{mTNF}}+\mathrm{N}$-acetyl-cysteine (NAC, 2mM) and then ROS level was quantitatively analyzed. (B) Cytotoxic effect of mTNFa on CD11b + cells decreased in the presence of ROS scavenger NAC. (C) Fluorescent micrographs of RAW 264.7 (blue: DAPI nuclear staining) incubated for 8 hours with FxB16 cont, FxB16 $6_{\text {cont }}+\mathrm{TNFa}$, or FxB16 $6_{\mathrm{mTNF}}$, FxB16 $6_{\mathrm{mTNF}}+\mathrm{NAC}(2 \mathrm{mM})$ and subsequently treated with ROS detection reagent, CM-H2DCFDA (green). (D) Intensity of CM-H2DCFDA was quantitated. Increase in number of ROS generating cell was detected in RAW 264.7 cocultured with mTNFa-expressing B16F10 cells which was reversed by addition of NAC. 
(E) Cytotoxic effect of mTNFa on RAW 264.7. $* P<0.05$, $* * P<0.005$ and $* * * P<0.0005,1-$ way ANOVA with Tukey's post-test. 
A

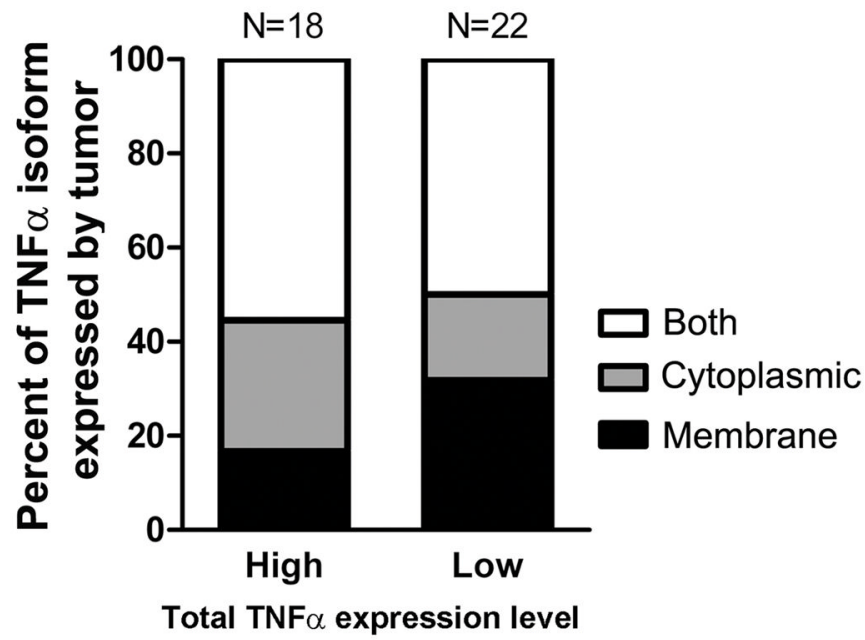

C
B

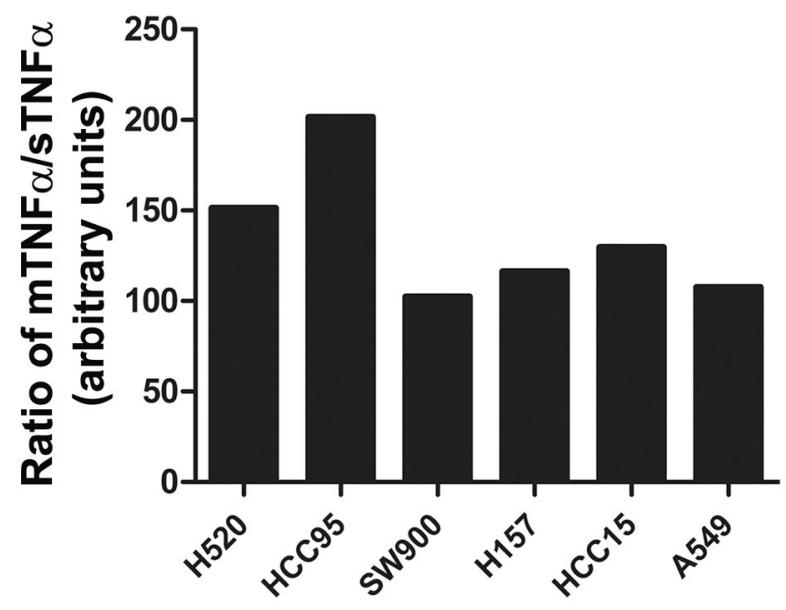

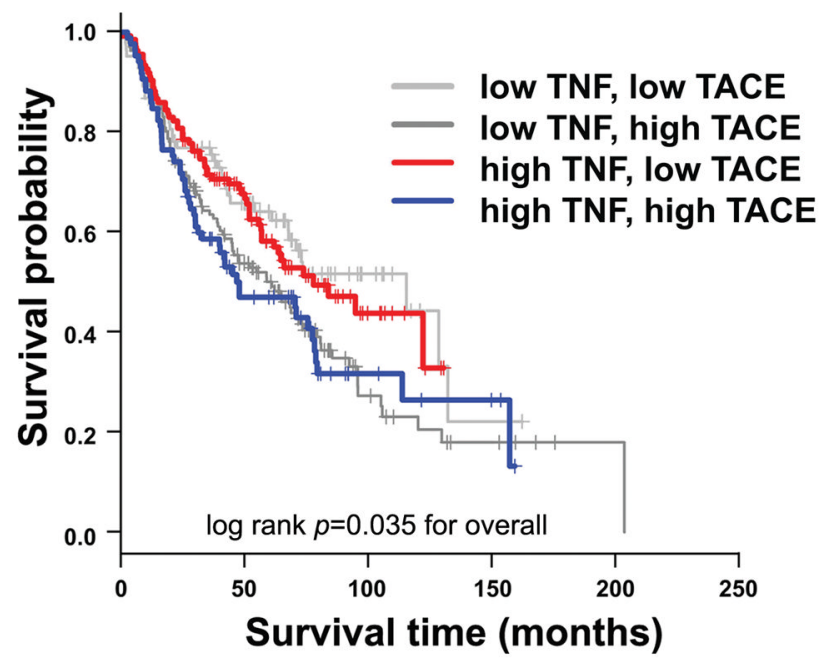

Figure 7. Relative expression pattern of TNFa/TACE correlates with survival probability in lung cancer patients

(A) Analysis of TNFa expression from 40 human non-small cell lung carcinoma (NSCLC) tissue array. Graph displays the distribution of both degree and localization of TNFa staining 40 NSCLC patient samples. (B) Expression pattern of sTNFa and mTNFa in human NSCLC cell lines measured by ELISA and immunoblotting methods, respectively. A significant variation was observed in the ratio of mTNFa to sTNFa expressed by each cell line. (C) Association between TNFa and TACE co-expression pattern and survival probability in patients with NSCLC. Analysis of the publicly available data from the Shedden cohort (17) was used to correlate TNFa/TACE expression pattern with survival probability $(\mathrm{n}=442$, log rank $P=0.035)$. 